\title{
Visual Literacy in High-Stakes Testing: Implications of Washback for Language Teachers
}

\author{
Visvaganthie Moodley \\ University of Witwatersrand, Johannesburg, South Africa
}

\begin{abstract}
The washback effects of high-stakes examination papers are critical in informing teaching and learning, and particularly those teachers who face compounded challenges of poor content knowledge and teaching in multilingual and multicultural English home language (EHL) classrooms. This paper examines the assessment of the visual literacy (VL) component of the EHL curriculum for Grade 12, school-exiting learners, as despite of its prolific presence in the media and society, VL poses severe challenges for teaching and learning. Drawing on the qualitative paradigm, I present a detailed analysis of 5 consecutive examination papers by focusing on the section, 'Language in Context' which comprises two questions: 'Analysing advertisements' and 'Understanding other aspects of the media'. The test design, specifically text selection and the questions asked, is analysed to address the following issues: the alignment of the assessment of VL with the EHL curriculum and the degree of authenticity of the assessment. I then consider the implications of the direction of washback for teachers. Mindful that research on washback underscores the interaction between tests, teaching and learning rather than the influence of tests on teaching, I conclude that while it is not possible to address all the goals of VL, both construct relevance and construct underrepresentation could be effective teaching tools for enhancing critical VL skills in the language classroom.
\end{abstract}

\section{Introduction}

Even though visual stimuli is prolific in societies worldwide and the teaching and learning of visual literacy (VL) is firmly established in language curricula, their practice poses a challenge in the complex linguistic landscape in the South African English home language (EHL) classroom. An increasing number of non-native English speaking learners opt to study English at HL proficiency level and an increasing number of under-trained teachers are positioned to teach VL at schools. Teaching in multilingual classrooms, of any combinations of the 11 official languages of South Africa (Afrikaans, English, Ndebele, Sepedi, Sesotho, Swati, Tsonga, Tswana, Venda, Xhosa and Zulu), compounds the challenges of teaching VL, as each learner brings different VL repertoires to the learning process.
Those from systemized language backgrounds (i.e., English and Afrikaans) carry rich schemata, built on a rich resource of visual materials for VL development, and those who hail from historically marginalized languages (i.e., the 9 African languages) come to the learning environment in deficit mode, a consequence of lack of visual resources [13]. The challenges coalesce with the language curriculum which explicitly outlines the goals and skills to be acquired in the teaching and learning of $\mathrm{VL}$ and the lack of professionally development programmes for ill-equipped teachers for affecting the planned curriculum. Within this complex linguistic landscape with its varying degrees of (il) literacy in visual reading, Moodley $[12$, p.220] states that teachers themselves 'who do not understand visual literacy concepts [] compensate for their deficits and challenges by teaching to examination papers'. On a broader note, Madaus [9, p.83] asserted that, 'It is testing, not the "official" stated curriculum, that is increasingly determining what is taught, how it is taught, what is learned, and how it is learned.'

Incited by this provocative declaration that challenges the position of cause and effect, I pursue the possibilities for the effect that test papers could have on teachers. In so doing, I was guided by Anderson and Wall's [1] view and that which is emphasized by Bachman and Palmer [2, p.109): 'we simply cannot assume that assessments will have an impact on teaching and learning, but must actually investigate the specific area' such as content of teaching, teaching methodology, ways of assessment, direction of washback, and extent of the presumed impact. Hence, I focus on the implications that the specific construct of visual literacy in high-stakes exams could have on teachers with regard to the direction of washback (i.e., benefits or damages). The objectives of this paper are thus to, in evaluating the congruence between the test design and the planned curriculum, determine the degree of authenticity of the tests as measured by Moodley's framework of authentic visual literacy assessment (VLA) [12]. Guided by Messick's [10] notion of '[seeking] validity by design as a likely basis of washback', I then consider and underscore the implications that the VLA have for the direction of washback for teachers. In an attempt at achieving these objectives, I hope to raise awareness of the need for research in visual literacy, its assessment 
and washback in South Africa as such studies are almost non-existent; most studies concern the test design itself rather than the consequences of the design on test-takers and their teachers.

\section{English home language curriculum}

To appreciate the impact of different VL knowledge schema of learners of diverse linguistic backgrounds; the challenges that teachers face in teaching VL; and teachers' growing dependence on past year exam papers as resource, it is necessary to allude to the language curricula before the demise of apartheid in 1994. The overt racist policies significantly influenced educational design, such that each of the four previously demarcated racial groups - Black, Coloured, Indian and White - was governed by distinctly segregated education departments viz., Department of Education and Training (DET), House of Representatives (HoR), House of Delegates (HoD) and National Education Department (NED), respectively, and the language syllabus for each emphasised different value and skills development. Of note is the treatment of language learning, which is encapsulated in Prinsloo's [14, pp.65-66] study of the differences between English, Afrikaans and Zulu language syllabi: In the English language syllabus for NED, "[The learner should be] aware of the various roles of English as a world language in science, technology, literature, diplomacy, etc.; and in the Zulu language syllabus for DET, 'Because the Bantu languages differ so much from the European languages, it is necessary that the Bantu child should not view his mother-tongue as if it were a European language'. The focus on mental processes in the former, together with pedagogy invoked in the use of such verbs as observe, see (relationships), discriminate and read (attentively, sensitively) and the absence of these in the African language syllabus, has constructed a dichotomous foundation for language learning which includes critical thinking - the cognitive skill crucial for reading and interpreting visual data. In addition, while media education was included in EHL curricula, it was only introduced to English second language (ESL) which was, primarily meant for Black SA learners. However, as stated at the outset, more and more nonnative English-speaking learners are opting to study English at home language proficiency level.

The National Curriculum statement (NCS), introduced in 2008 [5] and replaced with a new curriculum, Curriculum and Assessment Policy Statement (CAPS) in 2011 [6] embraced a democratic flavour that spanned all 11 official languages and specifically identified critical thinking as a key skill for all learners. Both the NCS and CAPS identified four learning outcomes, of which Reading and Viewing embeds visual literacy: The learner is able to read and view for understanding and to evaluate critically and respond to a wide range of texts. Crucial in promoting this skill is for learners to 'evaluate meaning and language critically in all texts and learn to appreciate and critique them' and 'viewing' which is 'often neglected in language teaching' is said to imply 'engagement with visual aspects of texts, such as pictures, symbols, graphs, cartoons, comic strips, posters and advertisements' [5, pp.18-19). The Grade 12, school-exiting learner, is expected to achieve the following skills, values and attitudes: (1) infer the meaning of unfamiliar words or images in familiar and unfamiliar contexts by using knowledge of grammar, word-attack skills, contextual clues, sound, colour, design, placement and by using the senses; (2) distinguish between fact and opinion, and motivate own response; (3) explain the socio-political and cultural background of texts; (4) recognize and explain the effect of a wide range of figurative and rhetorical language and literary devices such as metaphor, simile, personification, metonymy, onomatopoeia, symbol, puns, hyperbole, contrast, sarcasm, caricature, irony, satire, paradox, antithesis and anticlimax on the meaning of texts; and (5) interpret and evaluate a wide range of graphic texts and explain the effect of visual, audio and audio-visual techniques such as the use of colour, subtitles, dialogue, music, sound, lighting, editing, framing, styles of shot, composition, camera movement, camera techniques, foregrounding and backgrounding [5, pp.46-47].

The CAPS document, whilst retaining the above, is much more succinct in articulating the specific aims and skills of visual literacy for the Grade 12 learner: Learners should be enabled to use language, (1) as a means for critical and creative thinking; (2) for expressing their opinions on ethical issues and values; (3) for interacting critically with a wide range of texts; (4) for challenging the perspectives, values and power relations embedded in texts; and (5) for reading texts for various purposes, such as enjoyment, research, and critique, taking into account audience purpose and context [6, p.9]. The CAPS also states that in interpreting visual texts, learners must be taught the following: (1) persuasive techniques: emotive language, persuasion, bias, manipulative language; (2) how language and images reflect and shape values and attitudes; images and language that are sexist, racist, ageist, or depend on the reinforcement of stereotypes, especially in advertisements; (3) impact of use of font types and sizes, headings and captions; and (4) analyse, interpret, evaluate, and respond to a range of cartoons/comic strips [6, p.23]. Knowledge of both the NCS and CAPS is essential for the analysis of data for this paper as the data source is the NCS and the implications for washback would be for teachers of CAPS, the new curriculum. However, the intended curricula for $\mathrm{VL}$ are the same for both the NCS and CAPS and even though couched in 
different words, do not affect the validity of the assessment of the Grade 12 exam papers.

\section{Teaching and assessment of visual literacy in English language classroom}

The term 'visual literacy' eludes explicit definition as its hybrid nature appears to mean different things in different disciplines. Fransecky and Debes [8, p.7], however, provide a comprehensive definition that continues to be used in educational circles:

Visual literacy refers to a group of vision competencies a human being can develop by seeing at the same time he has and integrates other sensory experiences. The development of these competencies is fundamental to normal human learning. When developed, they enable a visually literate person to discriminate and interpret the visible actions, objects, and/or symbols, natural or manmade, that he encounters in his environment. Through the creative use of these competencies, he is able to communicate with others. Through the appreciative use of these competencies, he is able to comprehend and enjoy the masterworks of visual communication.

While this definition has paved the way for development in definitions over the decades, at its most general, VL can be said to be the ability to read and make interpretations of visual images in context. Implicit in the critical reading of visual texts is the notion of active meaning making, the interplay or negotiation in meaning between the text and the reader. Despite the pervasiveness of visual stimuli on $\mathrm{TV}$, magazines, newspapers, pamphlets, movies, smart phones and the like, and despite learners' engagement with the various visual elements, many learners - and indeed teachers -lack the ability to engage with visual texts in deep, complex and meaningful ways, and the increasing dominance of visual images in developing technologies present ongoing challenges for teaching and learning [12]. While there is no dearth in literature on how to read visual texts critically, there appears to be hardly any empirical evidence on its teaching and assessment in the language classroom.

For teaching VL, the ensuing question is: what specific content knowledge and what subtleties in language use must teachers recognize and know to promote visual literacy among their learners? In a study of assessment of VL across the official languages in South Africa, Moodley [12] found that one of the most significant challenges in VL pedagogy is teacher lack of specific pedagogical content knowledge. Herein, she raises the question, 'If teachers themselves lack knowledge and skills in decoding and encoding meanings of visual images, how then can learners be taught this knowledge and skills?' In designing a framework for teaching visual literacy, researchers such as Mbelani [11], drawing on constructivist theory, use Luke and Freebody's (1990), in [11], much-acclaimed Four Resource Model i.e. Code breaker, Text participant, Text user and Text analyst. He successfully demonstrates that visual texts could be analyzed as follows: (1) Code breaker: learners should be able to recognize technical features such as colour, position, artistic elements such as camera angle and shot, and style (e.g., headline, logo, slogan and font) and the purpose they serve. (2) Text participant: as a text participant, the reader uses his/her existing schema or cultural capital to interact meaningfully with new texts and engage in inter-textual practices and see relationships between the visual image and written text. (3) Text user: as texts are socially constructed compositions, learners should be familiarized with the social role of the visual text. (4) Text analyst: as visual texts are not neutral, learners should be taught to engage critically with the text, questioning the ideology presented in the text. This nondevelopmental, non-hierarchical framework is useful for teachers who experience challenges in teaching visual literacy.

A critical aspect of language pedagogy is assessment; it is inextricably woven with curriculum and classroom practice. It follows that if teachers experience significant challenges in teaching VL, then their assessment thereof will not be in synchrony with the intended curriculum. Consequentially, unconfident teachers tend to teach to past year exam question papers, replacing creative teaching and assessment practices [12]. However, Bachman and Palmer [2, p.108) note that even for proficient teachers who have specific pedagogical preferences, and who find that "if they have to use specified assessment, "teaching to the test" [is] unavoidable'. The profound role of assessments and more so high-stakes testing - cannot be underestimated, especially for those aspects of the curriculum where teachers lack content knowledge and pedagogical confidence. The assessment of VL therefore, particularly in high-stakes testing, is critical for its washback effect - a concept which is explored further on.

In developing a framework for authentic assessment for VL, guided by the principles of task specifications, [2, pp.313-319], Moodley [12, p.9] proposes five areas that are aligned with the curriculum: (1) Structural and organizational alignment of exam questions with curriculum: this is an important point of departure for authentic assessment - this is what is expected to be taught and teachers can expect these to inform summative assessment. (2) Text choices as critical instruments for authentic assessment: according to Moodley 'the identification of worthy visual texts is the most 
important consideration for examiners as these generate the kinds of questions [that, among other things] provide opportunities for examination candidates to demonstrate not 'correct' answers but engagement with the visual texts in multilayered ways. (3) Content-coverage as indicator of authentic assessment: the quality of questions asked 'is at the heart of the VL component of the [exam] paper' and includes 'both technical knowledge and language' such as the effect of fonts, appropriateness of slogans, emotive appeals and literary devices such as pun, satire, sarcasm and stereotype; interrelationships between the visual image and the written text; opinion-elicited questions that require justification; and creative questions.' (4) Cognitive levels of questions as indicators of high quality summative assessment: Moodley argues that 'cognitive levels and levels of difficulty within a domain affect the overall quality of an exam paper'. (5) Language and bias, and fairness in testing for validity: drawing on Umalusi's (the education quality assurance body of South Africa) framework of quality assurance, Moodley contends that language that is free of any form of bias (e.g., racial, cultural, gender, ethnicity, religion, language and the like) is an indicator of authentic assessment and contributes to fairness in testing. This is so because bias 'results in interpretations that are not equally meaningful, relevant, or generalizable for individuals in different groups' [2, p.129].

\section{Washback in assessment}

Over two decades ago, in their much-acclaimed article, 'Does washback exist?' - in which washback is seen to be traditionally entrenched in the belief that testing propels teaching and learning - Anderson and Wall [1, p.117] proclaimed that the concept was ill defined and called for further research in this area. Since then, experts in the field - such as Cheng, Watanabe and Curtis [4] - have proposed theoretically different positions of the phenomenon, but maintained its distinctive educational impact of high-stakes testing for institutions and individuals. While some argue for its positive effects to the extent that it can promote teaching and learning, others showcase its negative impact in impeding educational goals. However, like Wiseman [20], I find this dichotomous interpretation empirically limiting and suggest that a good teacher will identify benefits as well as recognize the limitations of a test when matched against the intended curriculum. Nevertheless, for this paper, I draw on definitions proffered by Messick [10, p.1] and Bailey [3, p.259], both of which are closely aligned with that proffered by Alderson and Wall [1]. Messick states that washback 'refers to the extent to which a test influences teachers and learners to do things they would not otherwise necessarily do' and Bailey simply states that it is 'the influence of testing on teaching and learning'. These definitions are particularly useful as they 'allow for both the accidental and intentional effects of washback and leave the door open on whether washback is positive or negative' [16, p.8]. The complexity of the phenomenon is evident in Alderson and Wall's [1, pp.120-121] presentation of 15 hypotheses - the potential results of testing each hypothesis will no doubt show an interplay of a network of factors that affect the washback effect from assessment. Of pertinence to this study, mindful that 'test design is only one [my emphasis] of the components in a quite complicated equation' $[17, \mathrm{p} .502)$, are the status of the subject in the curriculum [15]; teacher ability, teacher understanding of the test, classroom conditions, lack of resources and management practices within the school [1]; and teacher background [4].

In providing evidence for the positive direction of washback, Ferman [7, pp. 204-205] reports increased teacher focus on content, development of specific skills and employment of strategies that promote success. Also, as teachers and learners familiarize themselves with test patterns, their anxiety levels are alleviated. In addition, Pearson [13, p.98] suggests that 'good tests' could be used as teaching-learning activities; and Anderson and Wall [1, p.118) note, there is the 'possibility of a test reinforcing some behaviours or attitude' so that concepts that teachers already know could be reinforced. On the other end of the continuum, negative washback is 'the undesirable effect of on teaching and learning' of a 'poor test' i.e., a test to which teachers teach despite their own interests, understandings and belief [1, p.5]. One of the most significant negative effects of washback is that of constraining the curriculum or narrowing the scope of teaching to those aspects that are most generally tested [20, p.159; 1, pp. 126-127]. Wiseman (ibid) also notes that a reliance on existing test designs constrained time efficiency where the focus is on exam technique practice rather than language learning activities. Similarly, Ferman (ibid) highlights the negative impact in what he refers to as 'test score pollution' i.e., teaching towards 'an increase in test scores without a parallel rise in the ability in the constructs tested'. These concerns were also raised by Pearson (ibid) who states that negative washback is likely to occur when tests fail to reflect the learning principles and educational goals. Ideally, 'for optimal washback there should be little, if any difference between activities involved in learning the language and activities involved in preparing the test' [10, pp.241-242].

\section{Data and analysis}

This study falls in the qualitative paradigm but it has also drawn on quantitative analysis of the data 
sources. As such, the position this paper adopts is not a dichotomous one, as presented by Watanabe in an invaluable chapter Methodology in washback studies [18, pp.22-23], but one that uses the kinds of methodologies that are fit to purpose.

\subsection{Research design and data source}

This study is informed by 5 sets of Grade 12, school-exiting high-stake national, EHL examination papers with a focus on the VL aspects, as prescribed by DoE exam policy. These papers comprise 5 consecutive examinations viz., November 2011, March 2012, November 2012, March 2013 and November 2013. The November and March papers target a single cohort of candidates; those who sit for the March papers are either repeaters or those who have been granted deferments. The number of candidates who have written these papers are: November 2011, 85495; March 2012, 2077; November 2012, 95534; March 2013, 2261; and November 2013, 110243. A glance at these statistics suggests the high-impact these examinations are likely to have on teacher pedagogical content knowledge and behaviour in preparing future candidates for examinations. Each of the 5 papers comprises a question on advertisement and a question on cartoons. Even though both aspects share integral features, I analyze them separately as there are also explicit technical differences as well as subtle linguistic variations between the two. For ease of reference I refer to each of the 5 papers i.e., November 2011, March 2012, November 2012, March 2013 and November 2013 as Papers 1, 2, 3, 4 and 5 , respectively.

\subsection{Data Analysis Framework}

The principles that guided the investigation are as follow:

\subsubsection{Congruence between the planned} curriculum and test design. In determining the congruence between the planned curriculum and test design, the test was measured against the aims and objectives set out in the NCS that informed the examination papers. The key criteria, espoused in critical reading and viewing for specific purposes, pertain to: (1) socio-political and cultural background; (2) use of contextualization clues; (3) fact and opinion; (4) use of figurative and rhetorical devices; and (5) effectiveness of visual techniques. I use these criteria to inform the overall aim of 'critical reading and viewing'. The purpose of this analysis is to first assess the validity of the test design, as this will affect the degree of positive feedback. My hypothesis, identified as the first and third of Alderson and Wall's [1, p.120] 15 hypotheses viz.,
'A test will influence teaching' and 'A test will influence what teachers teach', respectively, is that if there is a significant correlation between the intended curriculum and test design, then the potential for positive washback for teachers is likely to be increased. I am mindful, however, of Anderson and Wall's [1] suggestion that the test is only one of numerous factors that influences the washback effect and its related complexities. The extenuating factors, however, is outside the domain of this study; the interpretation and discussion of findings is one of probabilities rather than empiricist.

5.2.2 Authenticity of the test design. Drawing on Moodley's (2014) [12] framework for authentic assessment of visual literacy, I focus on the following in analyzing the 5 examination papers: (1) Text choices as stimuli for generating questions for meaningful and critical engagement, for sociocultural inclusivity, and as indicators of fairness and validity. (2) Content specific knowledge viz., technical knowledge, jargon, critical language awareness, and interplay between the visual image and linguistic structures. (3) Language and bias. These criteria are informed by the principles of the intended curriculum, and a unified discussion of findings will therefore be presented.

5.2.3 Direction of washback for teachers of visual literacy. Once the findings for congruence between the planned curriculum and test design, and authenticity of the test design were ascertained, drawing on the literature on washback for educational profitability or negative influence, neither or both, the findings were mapped against the criteria identified in Table 1, below. As the dimension of washback in this study is specific in that it relates to only one specific test type $[19$, p. 20] i.e., visual literacy and one specific context (highstakes school-exiting national exams), wellacclaimed washback models are not functional for a study of implications. The criteria used are therefore hybrid, and develop from the features of Luke and Freebody's Four Resource Model for teaching, in [11], Moodley's authentic assessment of visual literacy [12], and existing body of knowledge on visual literacy. The six criteria are not discrete categories; rather, they are interrelated and progress towards evaluating the possibilities of washback effect on teachers. 
Table 1: Analytical framework for determining direction of washback

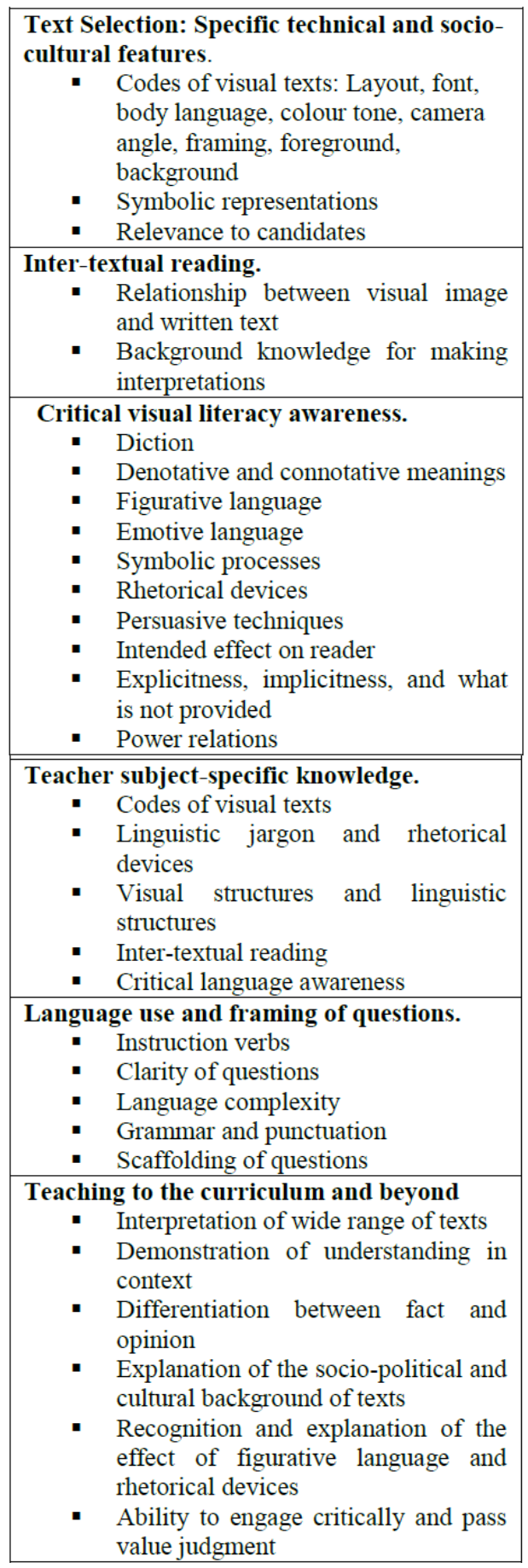

\section{Findings}

\subsection{Test design: Congruence with the planned curriculum and authenticity}

6.1.1 Text choices. At first glance of all 5 papers, the gaze falls on the pattern in the choice of the visual texts: one or two advertisements followed by one or two cartoons, totalling no more than three texts. Immediately, one sees that even though these choices are congruent with the curriculum, the repetitive and predictable genres lack correlation thereof; the exams exclude opportunities for candidates 'to interpret and evaluate a wide range of graphic texts [my emphasis]. The analysis of the visual images of the 5 advertisements (Investec Private Bank, Hi-Tec Footwear, 2 brands of Motor Vehicles, AIDS and Arrive Alive Campaign) and 7 cartoons (Madam and Eve [repeated]), Andy Capp, Blondie [repeated], Garfield, and Calvin and Hobbes), and their respective 20 and 21 questions, show that the choice of technical features and relevant questions include specificity in layout, black and white tones, framing, foreground, background and symbolic representations. Of the 41 questions analyzed, the data shows that while there are no explicit questions (except for a single question on a cartoon text) that address socio-political and cultural background of the texts, text choices themselves are rooted therein. The texts are authentic in that they are concerned with events and themes that are within the socio-political and cultural world views and cultural capital of the ideal grade 12 candidate. For example, the images for the advertisements of Paper 4 and Paper 5 deal with AIDS amongst children (Figure 1) and road safety (Figure 2), respectively; and the cartoons of Paper 1 (Figure 3) and Paper 5 deal with social scams and rhino poaching, respectively. In addition, the visual images and their accompanying linguistic texts can generate questions across specific VL skills and cognitive levels, as can be seen in the following examples:

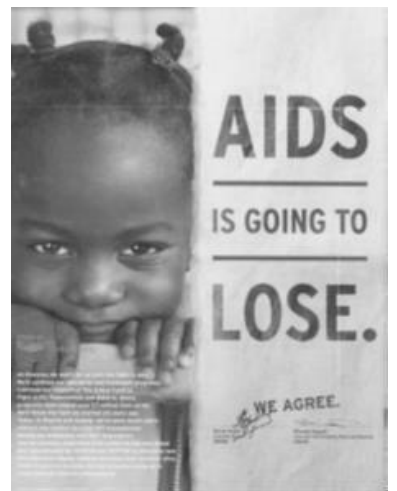

Figure 1: March 2013 (Paper 4) 


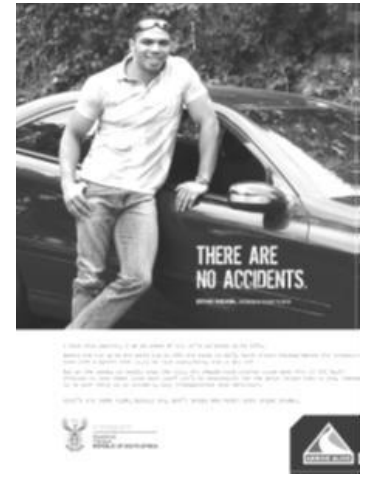

Figure 2: November 2013 (Paper 5)

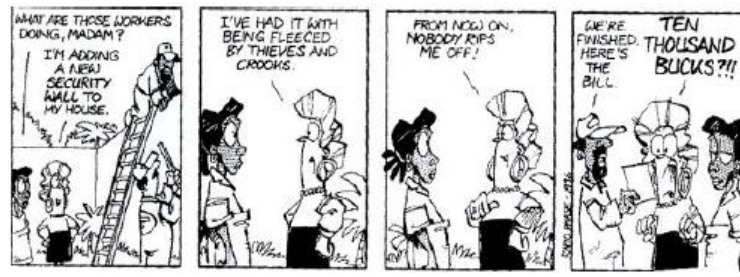

Figure 3: Madam and Eve, November 2011 (Paper 1)

Candidates are able to relate to such visual images instantly and this serves as a scaffold for negotiating meaning and engaging critically with the text holistically, thus rendering the test design authentic. For example, for the texts in Figures 1, 2 and 3, respectively:

(1) The text makes reference to both mother and child, but the photograph includes only an image of a child. In your opinion, is the photograph effective? Motivate your response.

(2) 'THERE ARE NO ACCIDENTS.' Critically discuss the effectiveness of the tone of this slogan in the context of the advertisement as a whole.

(3) Refer to frame 2. What do the idiomatic expressions, 'I've had it' and 'being fleeced', convey about Madam's attitude towards crime?

While text choices are authentic, they are limited in that they are constrained to advertising and cartoon reasoning; other genres of the visual media such as book covers, posters and graphs should be included to constrain predictability of text choices and defy the narrowing of the curriculum by teachers who teach to the tests.

\subsubsection{Contextualization clues and content specific} knowledge. Of the 5 advertising texts, 4 included a question on the use of contextualization clues. Candidates were required to 'describe the kind of reader to whom [the] advertisement would appeal' (Paper 1); comment on specific word choices in context (Paper 2); discuss the appropriateness of specific words in context (Paper 3); and account for the 'signatures of the Executive Director .... and the Executive Vice President ...' (Paper 4). The desirable responses are not straightforward and candidates are expected to use both visual and linguistic clues to answer the questions. With reference to the cartoons, even though there were no explicit questions on using contextualizing clues, all the questions required close contextual analysis to arrive at desirable responses. As regards the use of fact and opinion, there were no explicit questions thereof; however, these are implicit in questions on the use of figurative and rhetorical devices of which there were a total of 10 questions. In advertising, the questions focus on explanations of loaded key phrases, for example, 'Leadership is a verb' (Paper 1) and 'absolute life-saving' (Paper 2); and in the cartoons, questions on how humour is achieved (Papers 1, 2 and 3) and how language is used for effectiveness (Papers 3, 4 and 5) require making denotative and connotative interpretations. Other questions, more open-ended and situated in the use of figurative language and rhetorical devices, require critical engagement with 'style' (Paper 3), 'language' (Papers 3, 4 and 5), tone/irony/sarcasm (Papers 1, 2, 4 and 5), idiomatic expression (Paper 1) and attitudes (Paper 1), for example:

(4) Discuss how the phrase 'Absolute Lifesaver' is intended to influence the reader (Paper 2).

(5) Carefully read the written texts of [the two advertisements]. Critically discuss the effectiveness of the style and language in conveying the intention of each of the advertisers (Paper 3).

The majority of questions, are weighted in the effectiveness of advertising techniques (55\%) and cartoon reasoning techniques $(76 \%)$; some questions in advertising explicitly ask for a critical discussion of slogan (Papers 1, 4 and 5), font (Paper 2) and layout (Paper 4), for example:

(6) Explain whether the slogan, 'Out of the ordinary', is justifiable in terms of a claim made elsewhere in the text about the service being provided (Paper 1).

(7) Discuss the effectiveness as an advertising technique of the layout and language used in the headline, 'AIDS is going to LOSE' (Paper 4).

The remaining questions are more open-ended and require the candidate to draw on their subject content knowledge, for example:

(8) In your opinion, is the illustration a suitable choice for the product being advertised? Motivate your response (Paper 3).

In cartoon reasoning, all 5 papers tested in varying emphasis in depth of meaning making, expression and body language, relationship between the visual image and linguistic clues, how humour is achieved and techniques in conveying message or intention, for example:

(9) The cartoonist does not show the mother-in-law in any of the frames. Do you think that this is an effective technique? Motivate your response (Paper 1). 
(10) Suggest why the cartoonist has left a space between the two frames in the cartoon (Paper 2).

What is clear from the analysis is that not all questions are discrete in relation to the skill being tested; as can be seen in examples 1, 5, 6, 7 and 9, multiple skills are tested in a single item. The questions also clearly require content specific knowledge such as advertising and cartoon reasoning techniques; the ability to read both the visual image and linguistic clues in an interrelated way and for determining relationships between them; deep knowledge of figurative language and rhetorical devises; specific linguistic and visual literacy jargon; reading for inference-making of what is provided as well as what is excluded from the text; and on the whole engaging the candidate in critical reading and viewing. As such, even though not all the skills set out in the curriculum are directly addressed and there is a heavy slant in testing figurative language, rhetorical devices and genre specific techniques, all skills are assessed either explicitly or implicitly. The inclusion of VL specific content knowledge spread across the examinations point to the authenticity of the test design.

6.1.3 Language use and bias. Crucial to maintaining fairness and the standard of the paper is the complexity of language use for a home language paper and fairness for freedom from any form of bias. All questions demonstrate language use that is appropriate for the ideal Grade 12 candidate and freedom from any form of bias and/or stereotype. In addition, a glance at the examples provided show that the questions have clear instructional verbs, correctness in grammatical and punctuation use, and academic sophistication that are aligned with the curriculum. Furthermore, it shows that candidates must have jargon specific knowledge to be able respond accurately to the questions. Moreover, the exclusion of bias and questions that challenge stereotypes are reflective of authenticity in test design.

\subsection{Implications for the direction of washback for teachers of visual literacy}

The findings show that the 5 exam papers have implications for both positive and negative washback - for both the challenged and proficient teacher of visual literacy. The challenged teacher would be able to glean the essential elements of VL teaching and at worst, even though s/he might teach to it, the large majority of skills will be covered. However, this is most likely only if a series of test designs are used to teach to, as a single test cannot cover every skill. The benefits for the proficient teacher is escalated; s/he will reinforce the skills that are tested, and have the insights to recognize and teach that which have not been included in the test design but that which exists in the planned curriculum. The selection of texts would inform language teachers that these texts appear in everyday print media such as newspapers and magazines, and they could thus create their own resource pack. In addition, while reproducing texts in colour might not be economically viable, learners can be exposed to understanding variation in tone; the effects of foreground and background images; symbolical representations; and the importance for texts to be socio-politically and/or culturally learnerrelevant. Negatively, as only advertisements and cartoons appear for testing, other genres that are prolific in the visual media might not feature in the classroom, thwarting the alignment not only between the curriculum and classroom pedagogy, but also between out-of-school literacies and in-school literacies. The potential for positive washback is also evident in the numerous questions that require intertextual reading; teachers will recognize the need to teach learners to understand a visual text holistically by reading the visual image to the linguistic features and vice versa. In enhancing learners' abilities to make valid interpretations, teachers should also see the criticality of building on learners' existing knowledge and exposing them to a variety of socialpolitical-cultural experiences the more diverse the classroom the more likely the existence of knowledge gaps among individual learners. In addition, the various elements of critical visual literacy awareness - particularly diction, emotive language, symbolic processes, rhetorical devices, persuasive techniques and intended effect on the reader - feature often either explicitly or implicitly within a single question paper and across the papers showing that the direction of washback for teachers is a positive one. However, the omission of questions on power relations in the test design might influence a corresponding omission in teaching practice, constraining the curriculum. For the teacher who is challenged by language complexity that is appropriate for the home language learner, s/he could imitate the language of unambiguous questioning, grammar, style and punctuation. When the criteria of text selection, inter-textual reading, critical VL awareness and language use are viewed cohesively, the implications for positive washback for teacher subject-specific knowledge is strengthened; the illprepared VL teacher is obliged to take cognizance of what s/he knows and does not know; the former is reinforced and the latter must be learnt to fulfill his/her obligations to promoting VL skills in the classroom, not merely for test performance but for cognitive enhancement.

\section{Conclusion}

The analysis of the 5 consecutive visual literacy components of high-stakes, national school-exiting 
EHL exams point toward the potential for positive washback for teachers. However, my contention is that the direction of feedback, of any test or series of test designed for a single purpose, is not discrete but rather lies on a positive-negative continuum. A principal conclusion is that the teacher factor is critical for determining the direction of washback. The teacher who is challenged with the task of teaching visual literacy and who has limited specificcontent knowledge will benefit from the test: not only will s/he gain specific content knowledge by working through the series of exam questions but will be better positioned to teach it. However, it is likely that such a teacher will also experience the negative effects of washback; the teacher who teaches only to past year test papers constrains the curriculum. For the proficient teacher, positive washback is heightened; such a teacher will be positioned to reinforce recurring visual and linguistic features, align her/his teaching to the curriculum and even teach beyond it, as s/he addresses the pivotal goal of language teaching i.e., to engage the learner critically and creatively with reading texts. However, other teacher factors also influence what a teacher bears from tests to the classroom: teacher personal beliefs, past education and academic background are influential characteristics $[19$, p. 130]. Ideally, for the direction of washback to lean substantially to the positive, teachers should be familiar with the planned curriculum and have specific knowledge content to determine the degree of construct relevance and construct under-representation.

\section{References}

[1] Alderson, J.C. and Wall, D. (1993). Does washback exist? Applied Linguistics, 14(2), pp. 115-129.

[2] Bachman, L. and Palmer, A. (2010). Language assessment in Practice. Oxford: Oxford University Press.

[3] Bailey, K. (1996). Working for washback: a review of the washback concept in language testing. Language Testing, 13, pp. 257-279.

[4] Cheng, L., Watanabe, Y. and Curtis, C. (Editors). (2008). Washback in Language Testing. Research Contexts and Methods. New Jersey: Lawrence Erlbaum Associates, Inc.:

[5] Department of Education (DoE). (2008). National Curriculum Statement (NCS). Grades 10-12. General Subject Assessment Guidelines. Languages: Home Language, First Additional Language, Second Additional Language. Pretoria.

[6] Department of Education (DoE). (2011). National Curriculum Statement (NCS).Curriculum and Assessment Policy Statement (CAPS). Further Education and Training Phase. English Home Language. Grades 10-12. Pretoria.
[7] Ferman, I. (2008). The washback of an EFL national oral matriculation test to teaching and learning, in Cheng, L., Watanabe, Y. and Curtis, C. (Editors). (2008). Washback in Language Testing. Research Contexts and Methods, Mahwah, New Jersey: Lawrence Erlbaum Associates, Inc.

[8] Fransecky, R.B. and Debes, J.L. (1972). Visual literacy: A way to learn - a way to teach. Washington, DC: Association for Educational Communications and Technology.

[9] Madaus, G.F. (1988). The influence of testing on the curriculum. In Tanner, L.N. (Editor). Critical issues in the curriculum: eighty-seventh yearbook of the National Society of Education (Part 1), Chicago: University of Chicago Press.

[10] Messick, S. (1996). Validity and washback in language testing. Language Testing, 13(3), pp. 241-256.

[11] Mbelani, M. (2014). An investigation into the development of knowledge and strategies for the advancement of meaningful and critical teaching of visual literacy. Unpublished doctoral thesis, Rhodes University, Grahamstown.

[12] Moodley, V. (2014). Quality and inequality in the assessment of visual literacy in Grade 12 examination papers across six South African languages. Language Matters, 45(2), pp. 204-223.

[13] Pearson, I. (1988). Tests as levers for change, in Chamberlain, D. and Baumgardner, R.J. (Editors). ESP in the classroom: Practice and evaluation, (pp.98-107). London: Modern English.

[14] Prinsloo, J. (2001). Schooled inequalities - a comparison of the language syllabuses for English, Afrikaans and Zulu of the 1980s. Paper presented at International Literacy Conference. Cape Town, http://www.literacy.uct.ac.za/Papers/PrinslooPaper.html (18 February 2014).

[15] Shohamy, E., Donitsa-Schmidt, S. and Ferman, I. (1996). Test impact revisited: washback effect over time. Language Testing, 13, pp. 298-317.

[16] Spratt, M. (2005). Washback and the classroom: the implications for teaching and learning of studies of washback from exams. Language Teaching Research, 9(1), pp. 5-29.

[17] Wall, D. (2000). The impact of high-stakes testing on teaching and learning: can this be predicted or controlled. System, 28, pp. 499-509.

[18] Watanabe, Y. (2008). Methodology in washback studies, in Cheng, L., Watanabe, Y. and Curtis, C. (Editors). (2008). Washback in Language Testing. Research Contexts and Methods, Mahwah, New Jersey: Lawrence Erlbaum Associates, Inc.

[19] Watanabe, Y. (2008). Teacher factors mediating washback, in Cheng, L., Watanabe, Y. and Curtis, C. (Editors). (2008). Washback in Language Testing. 
Research Contexts and Methods, Mahwah, New Jersey: Lawrence Erlbaum Associates, Inc.

[20] Wiseman, S. (1961) (Editor). Examinations and English language. Manchester, England: Manchester University Press. 